\title{
The Widmanstätten Structure of Octahedral Meteoric Iron
}

\author{
By Prof. S. W. J. Smith, F.R.S., and J. Young
}

$\mathrm{T}$

HE effect known as the Widmanstätten structure is shown most clearly in those meteoric nickeliron alloys in which the percentage of nickel lies between certain limits, roughly, from 7 to 14 . When the percentage of nickel is less than about $6 \cdot 5$, there is no Widmanstätten structure the single component is known as 'kamacite'. With higher percentages of nickel, there is always an additional component-known as 'taenite'. Attempts to find its percentage composition by chemicalmethods led to very differentresults, ranging from about 25 to 37 -although in one isolated case a percentage of about 47.8 was recorded. These widely varying results are due to the difficulty of isolating the taenite from the kamacite with which it is so intimately mixed and indeed often encloses. It was for this reason that it occurred to one of us to attempt to determine the composition of the taenite in situ by means of 'thermo-magnetic' analysis (Phil. Trans., A, 1908).

For various reasons these early efforts were not so successful as they might have been. Later it was possible, in Birmingham, to repeat these experiments with more suitable meteorites than that originally examined and to add micrographic and $\mathrm{X}$-ray measurements to this method of attack. For the results obtained by the latter (Proc. Roy. Soc., A, 1926, etc.), one of us (J. Y.) has been almost entirely responsible; while Mr. A. A. Dee gave valuable help in the development of the former.

Of the various octahedrites examined, the Butler meteorite, containing about 10 per cent of nickel and relatively free from impurities such as phosphorus, gave the most satisfactory results. It showed in the clearest possible way that the taenite has a reversible magnetic transition temperature at about $500^{\circ} \mathrm{C}$. and therefore contains approximately 50 per cent of nickel. From the way in which it forms (see below), it is unlikely that a taenite band is of uniform composition. It may be sensibly less rich in nickel at its centre than at its boundaries. In any event, the thinnest bands are most likely to be of nearly uniform composition and to give the closest approximation to the equilibrium percentage of nickel in the $\gamma$ phase alloy.

In agreement with this consideration, X-ray analysis shows that the narrowest taenite bands contain the highest percentages of nickel-about 55 per cent in these and about 50 per cent in the broader bands. It does much more than this. It shows that kamacite and taenite are, apart from impurities, solid solutions of nickel and iron-the former having a body-centred and the latter a facecentred cubic lattice. The lattice parameters confirm the inference from the thermomagnetic experiments regarding the composition of taenite. Other results are particularly significant. They show that the majority of the taenite crystals have a single orientation throughout the meteorite, their $\{111\}$ planes lying nearly parallel to the kamacite-taenite lamellæ. The kamacite crystals show small random deviations from the twenty-four orientations of the type; (110) kamacite parallel to (111) taenite, [001] kamacite inclined at $4^{\circ}$ to $[01 \overline{1}]$ taenite. These relationships hold in both band and plessitic structures; but the deviations are greater in the latter than in the former.

A significant feature of the taenite bands, revealed by micrographic investigation, is that only the narrowest of these consist entirely of $\gamma$-phase alloy. The central regions of the broad bands often show that an independent $\gamma$ - $\alpha$-transition, sometimes described as 'plessite', has developed there. A char. acteristic feature of this development occurs where it meets the inner boundary of its taenite envelope. This boundary has a 'jagged' or serrated appearance -due no doubt to the conditions under which the last of the $\gamma$ - $\alpha$-transition occurs. It exhibits the traces on the surface of rational planes of the taenite containing a $[110]$ axis, such as $\{111\},\{100\},\{110\}$ and $\{211\}$.

One of the most interesting problems presented by the results is the magnetic behaviour of the taenite, which would have shown little, if any, magnetic evidence of its existence during the first heating experiments if a step-by-step method of heating to successively higher temperatures had not been used. X-ray analysis provides an explanation of this phenomenon. It reveals the existence in the meteorite 'as received' of a transition layer at the taenite-kamacite boundary in which the lattice spacings of planes parallel to that boundary vary continuously from that of the $\{111\}$ plane of the taenite to that of the $\{110\}$ plane of the kamacite. This transition layer is that at which the last of the $\gamma-\alpha$-conversion occurs as the temperature falls. It would seem that it is the effect produced by the heat treatment upon this layer that enables the taenite to exhibit its ferromagnetism.

Very suggestive results were obtained from a study of an artificial nickel-iron alloy containing 10 per cent nickel cooled slowly from the molten state. Magnetic and X-ray analysis of this alloy showed that it consisted entirely of body-centred crystals. When, however, the alloy was heated progressively to, and annealed at, a temperature of $580^{\circ} \mathrm{C}$., its subsequent behaviour indicated the presence of a $\gamma$-phase alloy containing about 30 per cent nickel. $\mathrm{X}$-ray examination confirmed the presence of $\gamma$ crystals having a strongly preferred orientation, in which their $\{111\}$ planes were parallel to the Widmanstätten figures in each grain, as in the meteorites. The $\alpha$-crystals also exhibited twentyfour orientations differing little from those found in the octahedral meteorites. Although cooling in liquid air transformed some of the $\gamma$-phase into $\alpha$, this is the nearest approach we have yet made to a reproduction of the essential features of an octahedral meteorite. Recent experiments by others support the view that a much closer reproduction would have been made by exceedingly slow cooling.

An interesting effect of the heat treatment of meteoric iron is the formation of slip planes in the taenite. These can be produced, for example, by heating to $650^{\circ} \mathrm{C}$. followed by cooling in liquid air. Slip planes of the forms $\{111\},\{100\}$ and $\{110\}$ are common and the direction of slip, when identified, 
is [110]. There can be little doubt that such slip planes arise as a result of the differential contractions of the constituents when cooled and of the expansion associated with the $\gamma-\alpha$-transformation when it occurs.

Finally, it may be of interest to summarize our views regarding the origin of the Widmanstätten structure in meteorites. It seems highly probable now that the kamacite lamellæ are the result of a $\gamma-\alpha$-lattice-mechanical transformation. This is shown by the relationship between the orientations of the kamacite crystals and the single orientation of the taenite, and is confirmed by the fact that approximately the same relationship is found in the 10 per cent artificial alloy in which the $\gamma$ - $\alpha$-transformation is known to have occurred.

As is commonly held, it is quite probable that meteorites have originated during extremely slow cooling inside some massive heavenly body. In these circumstances, the lattice-mechanical transformation may have taken place so slowly that almost perfect equilibrium has obtained. From this point of view the parameter measurements of the taenite are significant-showing that the narrowest taenite bands are always richer in nickel than the broader ones. It would seem that the latter, owing to their thickness, cannot attain complete equilibrium at the lowest temperature at which effective diffusion is possible.

Acknowledgment of the contributions of many postgraduate students to the work, here outlined very briefly, will be made elsewhere. It is the fault of one of us (S. W. J. S.) that it is so much overdue.

\section{Dimensions of Some Organic Molecules}

$\mathrm{T}$ $\mathrm{HE}$ forty-fourth Bedson lecture was delivered by Dr. J. Monteath Robertson to the Bedson Club at King's College, Newcastle-upon-Tyne, on January 27.

Under the title "The Dimensions of Some Organic Molecules", Dr. Robertson dealt with advances in this field, which have occurred mainly as a result of X-ray crystallography. A crystal may be regarded as a periodic structure of units containing electrons, which diffract $\mathrm{X}$-rays, and from a consideration of the direction of diffracted beams, it is possible to determine the distance between these units. By a more involved analysis of the intensities of the beams, something may be learnt about the distribution of the electrons within the diffracting units, and from this, the structure of organic molecules can be investigated. The results are worked out as a twodimensional graph of electron density, and although in general there is foreshortening owing to the molecule lying at an angle to the plane of projection, it is possible, by taking a series of projections, to obtain a true picture of the molecule in space. Upon such graphs, atoms, except hydrogen, the scattering power of which is insufficient for separate resolution, are clearly seen as circular regions of high electron density, and the peak values enable the separate atoms to be named. As a general rule, it is not possible to obtain the electron density graph without some assistance from chemical evidence, although in some cases the assistance is slight.

The results obtained may be classified under two heads; first, the qualitative confirmation of organic structures, and the refinement offered by the actual measurement of bond distances, and secondly, the information obtained with regard to the relative orientation and distance apart of the separate molecules in the crystals.

Bond measurements of organic compounds which can be represented by a unique structural formula show certain definite regularities. Both single and multiple bonds are constant in length, the atoms being nearer in multiple-bonded compounds than in single, and nearer in the case of nitrogen atoms than in the case of carbon. Bond distances between carbon and nitrogen atoms are the mean of the corresponding carbon-carbon and nitrogen-nitrogen distances. These regularities are not found where resonance is possible.
In such cases, the length of a single bond may have any value intermediate between those normal for single and double bonds. In some of the simpler cases it is possible to estimate bond distances by wave mechanics, and their actual measurement provides a very important check upon these highly involved theoretical calculations. Such measurements also played a very important part in the development of the theory of resonance.

With regard to intermolecular distances in crystals, we may also distinguish two groups, normal and abnormal. In the first, typified by the hydrocarbons, the molecules appear to be arranged in the most convenient manner, without any particular order, and the distances of nearest approach are of the same order for a great many compounds. In such substances as benzoquinone, as might be expected, the dipole causes some approximation of oppositely charged atoms, but the distance of nearest approach is not greatly reduced. In the second group (abnormal), the approach distances are less by nearly an angström unit, and this applies generally to those compounds which are known to be associated in the liquid or gaseous states. In the case of resorcinol, for example, very drastic changes are found. The molecules are orientated so that the hydroxyl groups come much nearer to each other than is normal. The structure itself, however, remains open, as is shown by the fact that resorcinol is less dense than benzoquinone. This indicates the strongly directive power of the intermolecular hydroxyl 'bonds', which can maintain such an open arrangement. However, when resorcinol is heated above $74^{\circ} \mathrm{C}$., thermal agitation destroys this structure, the molecules are arranged without reference to the affinities of the hydroxyl groups, and the density rises. The higher temperature form takes several weeks to revert to the other, and can be studied in the usual way, when it is found that the molecules are arranged in much the same way as in a hydrocarbon crystal. The close approach of hydroxyl groups is very common, and in the case of hydrated oxalic acid, for example, it is thought that intermolecular resonance occurs.

In conclusion, Dr. Robertson said his intention had been to show that the newer developments of $\mathrm{X}$-ray crystallography enable a definite and accurate picture of the molecular structure to be obtained. 